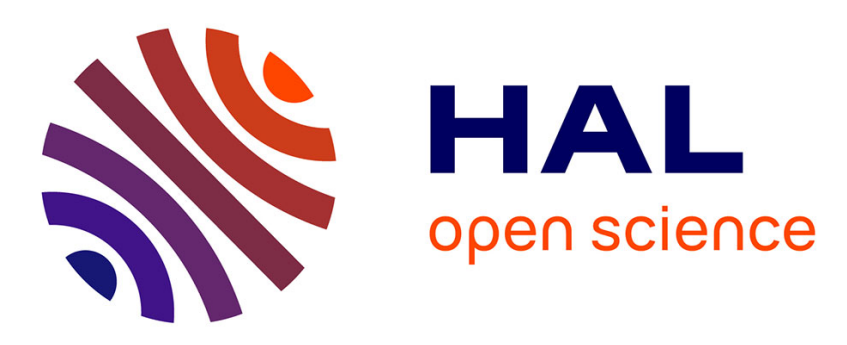

\title{
Core-Shell Spheroidal Hydrogels Produced via Charge-Driven Interfacial Complexation
}

\author{
Vincenzo Calabrese, Davide Califano, Marcelo da Silva, Julien Schmitt, \\ Saffron Bryant, Kazi Hossain, Ana Percebom, Aurora Pérez Gramatges, Janet \\ Scott, Karen Edler
}

\section{To cite this version:}

Vincenzo Calabrese, Davide Califano, Marcelo da Silva, Julien Schmitt, Saffron Bryant, et al.. CoreShell Spheroidal Hydrogels Produced via Charge-Driven Interfacial Complexation. ACS Applied Polymer Materials, 2020, 2 (3), pp.1213-1221. 10.1021/acsapm.9b01086 . hal-03037645

\section{HAL Id: hal-03037645 https://hal.science/hal-03037645}

Submitted on 23 Nov 2021

HAL is a multi-disciplinary open access archive for the deposit and dissemination of scientific research documents, whether they are published or not. The documents may come from teaching and research institutions in France or abroad, or from public or private research centers.
L'archive ouverte pluridisciplinaire $\mathbf{H A L}$, est destinée au dépôt et à la diffusion de documents scientifiques de niveau recherche, publiés ou non, émanant des établissements d'enseignement et de recherche français ou étrangers, des laboratoires publics ou privés. 


\title{
Core-Shell Spheroidal Hydrogels Produced via Charge-Driven Interfacial Complexation
}

\author{
Vincenzo Calabrese, ${ }^{*}$ Davide Califano, Marcelo A. da Silva, Julien Schmitt, Saffron J. Bryant, \\ Kazi M. Zakir Hossain, Ana M. Percebom, Aurora Pérez Gramatges, Janet L. Scott, and Karen J. Edler*
}

Cite This: ACS Appl. Polym. Mater. 2020, 2, 1213-1221

Read Online

\section{ACCESS \\ Џlll Metrics \& More \\ | 回 Article Recommendations \\ | S1 Supporting Information}

ABSTRACT: Through charge-driven interfacial complexation, we produced millimeter-sized spheroidal hydrogels $(\mathrm{SH})$ with a core-shell structure allowing long-term stability in aqueous media. The $\mathrm{SH}$ were fabricated by extruding, dropwise, a cationic cellulose nanofibril (CCNF) dispersion into an oppositely charged poly(acrylic acid) (PAA) bath. The SH have a solid-like CCNF-PAA shell, acting as a semipermeable membrane, and a liquid-like CCNF suspension in the core. Swelling behavior of the $\mathrm{SH}$ was dependent on the osmotic pressure of the aging media. Swelling could be suppressed by increasing the ionic strength of the media as this enhanced interfibrillar interactions and thus strengthened the outer gel membrane. We further validated a potential application of $\mathrm{SH}$ as reusable matrixes for glucose oxidase (GOx)

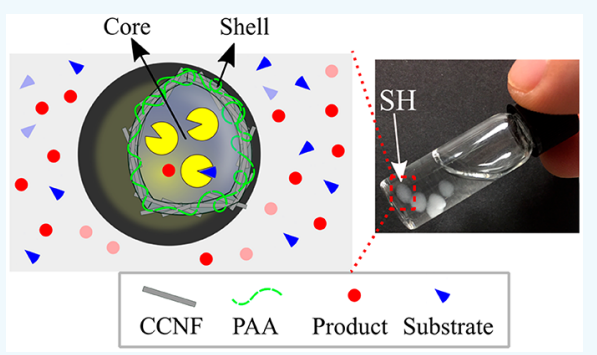
entrapment, where the $\mathrm{SH}$ work as microreactors from which substrate and product are freely able to migrate through the $\mathrm{SH}$ shell while avoiding enzyme leakage.

KEYWORDS: complex precipitate, cellulose, enzyme entrapment, glucose oxidase, biocatalysis

\section{INTRODUCTION}

Segregative phase separation is a common phenomenon observed upon mixing of oppositely charged polyelectrolytes. ${ }^{1}$ When two oppositely charged polyelectrolytes are mixed, they spontaneously form a polyelectrolyte-rich segregated phase, named a complex coacervate or complex precipitate, and a polyelectrolyte-poor coexisting phase containing mainly uncomplexed polyelectrolytes. This behavior is the consequence of the favorable mixing enthalpy and increased entropy due to counterion release. ${ }^{2,3}$ Chollakup et al. established a phenomenological-based difference between complex coacervates and complex precipitates, the first being liquid-like while the second is solid-like. ${ }^{4}$ Since the first theoretical description of charge-driven polyelectrolyte complexation by Voorn and Overbeek, ${ }^{1}$ many studies focused on the applicability of the theory for well-defined polyelectrolytebased systems. ${ }^{2,5}$ Nevertheless, complex coacervates and complex precipitates produced by mixing of soluble polyelectrolytes with dispersed colloidal mixtures have also been reported. ${ }^{3}$ The formation of complex coacervates or precipitates depends on the molar ratio, $f=c^{+} /\left(c^{+}+c^{-}\right)$, between the positively $\left(c^{+}\right)$and negatively $\left(c^{-}\right)$charged moieties, where $f=$ 0.5 corresponds to a $1: 1$ stoichiometric ratio while $f>0.5$ and $f$ $<0.5$ correspond to the excess of polycation or polyanion, respectively. 5,6 Spruijt et al. showed that independent of the polycation/polyanion molar ratio, the coacervate maintains an equimolar ratio $(f \cong 0.5)$, and the excess polyelectrolyte stays in the coexisting phase. ${ }^{6}$ Ionic strength and $\mathrm{pH}$ are also crucial factors in the formation and stability of coacervates or precipitates with the coexisting phase. , $^{2,5,7}$ For instance, Hamad et al. demonstrated that by increasing the ionic strength, the coacervate exhibited a more liquid-like behavior; they attributed this to the lowering of the electrostatic attraction between oppositely charged moieties, thus facilitating chain motion. ${ }^{5}$

The charge-driven complexation of polyelectrolytes and colloids has been broadly employed for the fabrication of capsules and drug carriers. ${ }^{8,9}$ This method exploits the labile nature of the physical cross-links to fabricate materials with mechanical properties that depend on external stimuli (e.g., $\mathrm{pH}$ and ionic strength). Charge-driven complexation has been successfully extended to two immiscible phases, often termed interfacial complexation. ${ }^{10,11}$ In this case, one charged species is solubilized or dispersed in one phase (e.g., water), with an oppositely charged species in the second immiscible phase (e.g., oil); the two species then complex across the liquidliquid interface. This method has been shown to form strong interfaces, ${ }^{12}$ resulting in the formation of stable emulsions and microcapsules. $^{10,11}$

Analogously to the interfacial complexation method, we utilize the charge-driven complexation of cationic cellulose nanofibrils (CCNF) and poly(acrylic acid) (PAA) as a simple

Received: November 14, 2019

Accepted: February 12, 2020

Published: February 12, 2020 
methodology to fabricate millimetric spheroidal hydrogels (SH) with long-term stability in aqueous and saline media; this method relies on the formation of a complex precipitate at the $\mathrm{SH} /$ water interface, with a solid-like shell (SH-shell), and a liquid-like core (SH-core) composed of uncomplexed particles. Similar core-shell structures have been previously reported, for instance, by coextruding an alginate solution around a second liquid phase and precipitating the core-shell droplet into a divalent cation bath (sometimes termed ionotropic gelation ${ }^{13}$ ), leading to the gelation of the alginate around a liquid core. ${ }^{14,15}$ Although these structures have long-term stability in water, they have a limited life span in the range of just a few minutes when stored in a monovalent electrolyte solution, even at concentrations as low as $10 \mathrm{mM}$, due to alginate dissolution. ${ }^{14}$ The use of charge-driven complexation for the production of core-shell structures at the micro- and nanoscale has been broadly reported, ${ }^{16}$ while to our knowledge, stable macroscopic core-shell porous hydrogels have only been reported using a combination of ionotropic gelation and charge-driven complexation of oppositely charged species. ${ }^{17-19}$ Macroscopic core-shell hydrogels offer applications in tissue engineering, cell culture, and controlled delivery of active excipients. Core-shell hydrogels are potential microreactors for biocatalysis from which substrate and product are freely able to migrate through the shell while avoiding enzyme leakage. In contrast to common microreactors containing covalently immobilized enzymes on a substrate, the physical enzyme entrapment in the liquid-like core enables high-performance biocatalysis due to the fast diffusion of targeted species (e.g., product and substrate) from and/or into the hydrogel while overcoming drawbacks related to costs, laborious purification procedures, and preservation of the native enzymatic conformation. ${ }^{20-22}$ Driven by the potential applications of $\mathrm{SH}$ in biotechnology applications, we investigate the structure-property relationship of cellulosebased $\mathrm{SH}$ in relevant conditions and provide a proof-ofconcept application of $\mathrm{SH}$ as matrixes for enzyme entrapment.

\section{MATERIALS AND METHODS}

Fabrication of Spheroidal Hydrogels. Preparation of the CCNF via grafting of the glycidyltrimethylammonium chloride (GTMAC) ( $\geq 90 \%$, Sigma-Aldrich) was conducted as previously described using $\alpha$-cellulose (product number C8002, SigmaAldrich) ${ }^{23}$ following the semidry protocol of Zaman et al., ${ }^{24}$ resulting in a degree of substitution of $26 \%$ as measured by conductometric titration (presented in the Supporting Information, Figure S1). ${ }^{25}$

To fabricate the $\mathrm{SH}$, a 2.0 wt \% CCNF dispersion ( $\mathrm{pH} 7)$ was extruded, dropwise $(17.8 \pm 0.2 \mu \mathrm{L})$, into $50 \mathrm{~mL}$ of $0.1 \mathrm{wt} \%$ PAA (Sigma-Aldrich, $M_{\mathrm{v}} \sim 450 \mathrm{kDa}$ ) aqueous solution by using a syringe equipped with a blunt end polypropylene dispensing tip (Fisnar Inc., gauge 21, inner diameter $0.513 \mathrm{~mm}$, the tip positioned at ca. $2 \mathrm{~cm}$ from the PAA solution-air interface), and the $\mathrm{SH}$ was aged for $5 \mathrm{~min}$ except where stated otherwise. A maximum of $50 \mathrm{SH}$ were produced using the same PAA bath to ensure a large excess of the polyanion (estimation of $f$ presented in the Supporting Information). The SH were thoroughly rinsed in deionized (DI) water $(18.2 \mathrm{M} \Omega \mathrm{cm})$ to remove any excess PAA before every experiment. All the experiments were conducted at $\mathrm{pH} 7$ excepted where stated otherwise. Under these conditions, PAA bears a negative charge due to the $\mathrm{RCOO}^{-}$ moiety ${ }^{26}$ while CCNF bears a positive charge due to the $\mathrm{NR}_{4}^{+}$ group. ${ }^{24,27} \mathrm{~A}$ schematic representation of the $\mathrm{SH}$ fabrication and their structure is presented in Figure 1.

Imaging. To image the $\mathrm{SH}$-shell, the $\mathrm{SH}$ were fractured on a glass slide, and images were acquired by using an optical microscope (Brunel Ltd. SP200 equipped with a Canon EOS 1300D). The

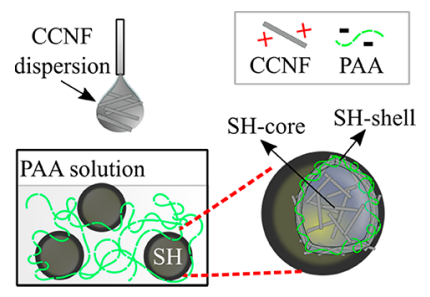

Figure 1. Schematic representation of the SH fabrication in the PAA solution and their structure.

intensity profile (in arbitrary units) as a function of distance was measured by using the "plot profile" tool in ImageJ. ${ }^{28}$

Leakage and Retention of Surface-Active Molecules. The retention of amphiphilic nonionic species within the $\mathrm{SH}$ was probed via surface tension ( $\mathrm{Du}$ Noüy ring method). A series of $2.0 \mathrm{wt} \%$ CCNF dispersions were loaded with $500 \mu \mathrm{M}$ Pluronic F-127 $\left(M_{\mathrm{w}}=\right.$ $12.6 \mathrm{kDa})$ (F-127), $5 \mu \mathrm{M}$ 2-hydroxyethylcellulose $\left(M_{\mathrm{w}} \sim 380 \mathrm{kDa}\right.$, 2HEC-380, Sigma-Aldrich), or $0.5 \mu \mathrm{M}$ 2-hydroxyethylcellulose $\left(M_{\mathrm{w}}\right.$ $\sim 1300 \mathrm{kDa}, 2 \mathrm{HEC}-1300$, Sigma-Aldrich). The $\mathrm{SH}$ were produced as previously described, and, a specific number of $\mathrm{SH}$ aged for 3 days in $50 \mathrm{~mL}$ of $100 \mathrm{mM} \mathrm{NaCl}$ solution (respectively 1,3 , and $3 \mathrm{SH}$ for the F-127, 2HEC-380, and 2HEC-1300). The concentration of the amphiphilic species in the CCNF dispersion, as well as the number of $\mathrm{SH}$ aged in the same vial, was chosen to (i) allow detection at the water-air (W/A) interface, (ii) avoid saturation of the W/A interface, and (iii) be as low as possible to avoid significant change in the $\mathrm{SH}$ structure. Then, the W/A surface tension $(\gamma)$ of the aging media was measured before and after SH breakage by using the Du Noüy ring method (Sigma 701 instrument, Attension, Sweden, equipped with a $9.58 \mathrm{~mm}$ platinum ring and a vessel of $66 \mathrm{~mm}$ in diameter). Breakage of the $\mathrm{SH}$ was conducted by employing a homogenizer (Ultra Turrax, IKA T25 digital, $30 \mathrm{~s}$ at $6500 \mathrm{rpm}$ ). Unloaded SH were employed as controls to ensure that the $\mathrm{SH}$ on their own did not affect $\gamma$ before or after breakage. The data presented were obtained from two separate repeat experiments.

Swelling Rate. Immediately after the fabrication of the $\mathrm{SH}$, their swelling was monitored by placing them in quartz cuvettes $(1 \times 1$ $\mathrm{cm}^{2}$ ) containing $1 \mathrm{~mL}$ of different continuous phases (DI water, 0.1 wt $\%$ PAA, and $1000 \mathrm{mM} \mathrm{NaCl}$ solution) and pictured over time (by using a drop shape analyzer, DSA30R). From the pictures, the area of the SH ( $A$, in pixels) was obtained through image analysis conducted using the "analyze particles" tool in Image ${ }^{28}$ and normalized as $A_{i} / A_{0}$, where $A_{i}$ is the area at time $=i$ and $A_{0}$ the area at time $=0$. In the case of the $\mathrm{SH}$ rupture, the expelled aggregates were not considered as part of $A_{i}$; only the shell remnants were measured, giving large variation in $A_{i}$ after rupture due to irregular changes in osmotic pressures between the $\mathrm{SH}$-core and the media. The presented data were obtained from three separate experiments.

Osmotic Pressure. To study the effect of the osmotic pressure of the continuous media $\left(\Pi_{\mathrm{m}}\right)$ on the swelling properties of the $\mathrm{SH}$, the swelling ratio (SR) of the SH aged in different media was obtained gravimetrically as $\mathrm{SR}=W_{\mathrm{SH}} / W_{\text {droplet }}$, where $W_{\mathrm{SH}}$ is the weight of a single $\mathrm{SH}$ and $W_{\text {droplet }}$ is the weight of a droplet of the CCNF dispersion used to fabricate $\mathrm{SH}$. To obtain $W_{\mathrm{SH}}$, the $\mathrm{SH}$ were removed from the aqueous media and placed in a weighing boat, and the excess of water was removed with the aid of a filter paper prior to measurement. A SR of $>1,<1$, and $=1$ corresponds to swelling, deswelling, and equilibrium, respectively. SH were separately aged in $2 \mathrm{~mL}$ solutions containing various concentrations of either $\mathrm{NaCl}$ or poly(ethylene glycol) (PEG) $\left(M_{\mathrm{n}}=0.4 \mathrm{kDa}\right.$, Sigma-Aldrich, Lot \#BCBN5570 V) for 3 days at room temperature. Concentrations of $\mathrm{NaCl}$ and PEG were chosen to generate similar osmotic pressures, $\Pi_{\mathrm{m}}$. The $\Pi_{\mathrm{m}}$ of $\mathrm{NaCl}$ solutions was calculated by using the van't Hoff equation, $\Pi_{\mathrm{m}}=M R T$, where $M$ is the molarity $(\mathrm{mol} / \mathrm{L}), R$ is the gas constant $\left(8.31 \times 10^{3} \mathrm{~Pa} \mathrm{~L} /(\mathrm{mol} \mathrm{K})\right)$, and $T$ is the temperature $(\mathrm{K})$. The $\Pi_{\mathrm{m}}$ of PEG solutions was instead calculated by using the empirical equation derived by Stanley and Strey. ${ }^{29}$ The data shown are the average of five separate experiments. 

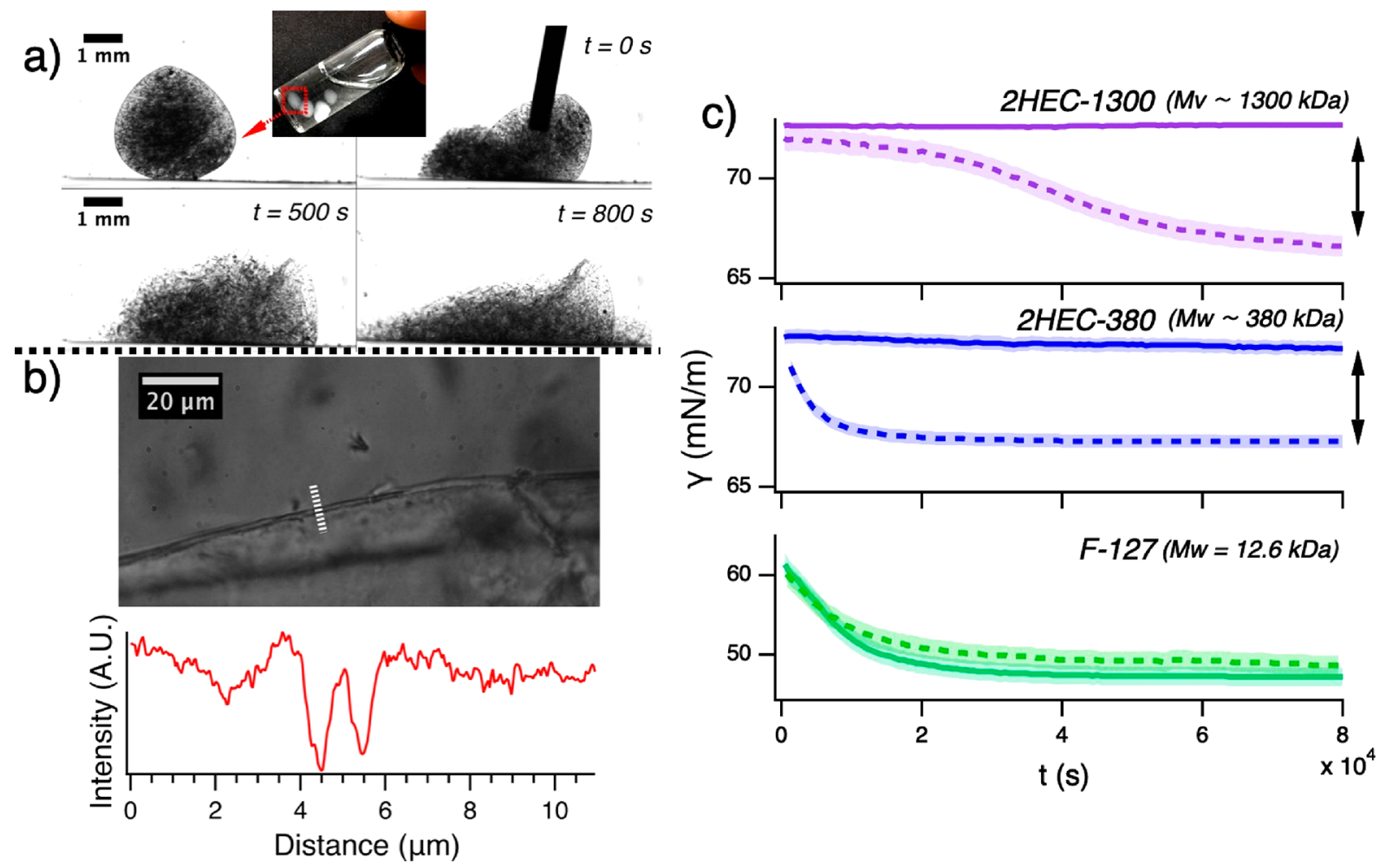

Figure 2. (a) Images of the SH suspended in DI water before rupture, at the time of rupture, and after 500 and $800 \mathrm{~s}$ from rupture (top left, top right, bottom left, and bottom right, respectively). (b) Optical microscope image of the SH-shell (top) and the intensity profile of the SH-shell cross section as indicated by the white dotted line (bottom). (c) $\gamma$ as a function of time for SH loaded with 2HEC-1300 (top), 2HEC-380 (center), and F-127 (bottom), before (filled line) and after rupture (dashed line). The standard deviation of duplicate samples is indicated by the shadow.

Oscillatory Rheology. The rheological measurements of $2.0 \mathrm{wt} \%$ CCNF hydrogels (prepared by diluting the CCNF stock dispersion with $\mathrm{DI}$ water and a $2.5 \mathrm{M} \mathrm{NaCl}$ solution) were performed by using a stress-controlled rheometer (Discovery HR3, TA Instruments) equipped with a sandblasted stainless-steel plate-plate geometry $(40 \mathrm{~mm})$. Strain sweep experiments were conducted at $1 \mathrm{rad} \mathrm{s}^{-1}$ angular frequency, and the $\tan \delta\left(\tan \delta=G^{\prime \prime} / G^{\prime}, G^{\prime}\right.$ being the storage modulus and $G^{\prime \prime}$ the loss modulus) was obtained from the linear viscoelastic region. The reported values are obtained from duplicate samples.

$\zeta$-Potential. The $\zeta$-potential measurements were performed using a Malvern Zetasizer Nano ZSP (Malvern, UK), and the $\zeta$-potential was evaluated via the Smoluchowski approximation. The Smoluchowski approximation is independent from the particle shape for the case of $k a>10$, where $1 / k$ is the Debye length and $a$ is the radius of the rod. This means that for particles with a small double layer and large $a$ the Smoluchowski equation can be used independently from the particle shape. For the present case of CCNF at different $\mathrm{NaCl}$ concentrations, the Smoluchowski equation is expected to be in its limits of validity only in the absence of $\mathrm{NaCl}$ (where $1 / k$ would be on the order of a few nanometers) while gaining reliability upon $\mathrm{NaCl}$ addition where the Debye length thins and the case of $k a>10$ is satisfied. ${ }^{30,31}$

CCNF dispersions were prepared at 0.02 wt \% at different $\mathrm{NaCl}$ concentrations and placed in the folded capillary electrode cell, and the $\zeta$-potentials measured as an average of four measurements from 100 scans each. The $\zeta$-potential values reported here were obtained from the average of three separate samples.

Small-Angle X-ray Scattering (SAXS). SAXS measurements on films of CCNF-PAA complexes that mimic the droplet interface were performed at Diamond Light Source (Didcot, Oxfordshire, UK), on the $\mathrm{I} 22$ beamline (beam energy $E=12.4 \mathrm{keV}$ and wavelength $\lambda=1$ $\AA$ ). The data were collected by using a Pilatus P3-2M (silicon hybrid pixel detector, DECTRIS) with a total acquisition time of $7 \mathrm{~s}$ (as an average of multiple frames of $100 \mathrm{~ms}$ ). The CCNF-PAA film was prepared by pouring, dropwise, $50 \mathrm{~mL}$ of $0.1 \mathrm{wt} \%$ PAA solution into $25 \mathrm{~mL}$ of $0.5 \mathrm{wt} \%$ CCNF dispersion under continuous stirring, allowing complete complexation of the oppositely charged moieties (and excess of uncomplexed PAA $(f \cong 0.19))$. The complex precipitate was compressed between two stainless-steel plates with the aid of a rheometer (Discovery HR3, TA Instruments) to form a film of $\sim 1 \mathrm{~mm}$ thickness and thoroughly rinsed with DI water to remove any excess of uncomplexed PAA, prior to aging in a concentration series of $\mathrm{NaCl}$ solutions. After $48 \mathrm{~h}$ aging SAXS measurements were performed. The wet films were removed from their media, placed in a film holder, and measured in air. The time between sample loading and measurement was kept below $5 \mathrm{~min}$ (allowing for hutch search and motor movement), avoiding significant drying of the sample. The SAXS pattern of the $2.0 \mathrm{wt} \%$ CCNF dispersion was obtained after loading the suspension into glass capillary tubes (Capillary Tube Supplies Ltd.) of $1.5 \mathrm{~mm}$ external diameter. All the scattering data were background subtracted and transmission corrected; for the CCNF dispersion the SAXS pattern was corrected for the capillary and solvent contribution. CCNF-PAA films were modeled as fractal aggregates composed by cylindrical building blocks of radius $R$, length $L$ corresponding to the characteristic node-to-node distance between cylinders, mass fractal dimension $D$, and a correlation length of the aggregate $\xi$, which defines the fractal length scale (i.e., aggregate size). This model couples the form factor of randomly oriented homogeneous cylinders, $P_{\text {cyl }}(q)=P_{\text {cyl }}(q, R, L)$, with a structure factor, $S(q)=S(q, \xi, D)$, describing a fractal structure as derived by Teixeira, ${ }^{32}$ to compute the scattering intensity $I(q):^{33,34}$

$$
I(q) \propto P_{\text {cyl }}(q) S(q)
$$

To reduce the number of fitting parameters, $R$ was extracted from the fitting of the scattering pattern of CCNF dispersion at $2.0 \mathrm{wt} \%$ in the high- $q$ region by using the $P_{\text {cyl }}(q)$ model (scattering pattern of CCNF in Figure S2). It was then fixed to $2.0 \mathrm{~nm}$ for the study of the CCNFPAA films-this length scale being in close agreement with our 


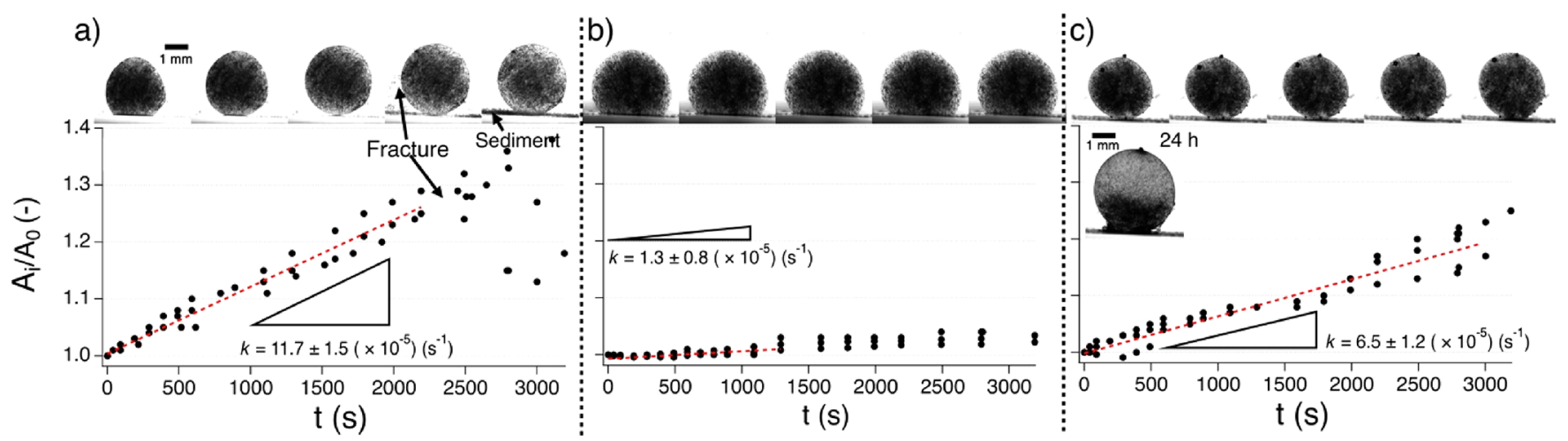

Figure 3. Aging of SH in (a) DI water, (b) $1000 \mathrm{mM} \mathrm{NaCl}$, and (c) $0.1 \mathrm{wt} \% \mathrm{PAA}$. SH images are shown on the top of the graphs in line with the time evolution indicated by the $x$-axis. Dotted lines indicated the region where the linear fittings were adopted to calculate the swelling rate, $k=\frac{\mathrm{d}\left(A_{i} / A_{0}\right)}{\mathrm{d} t}$. Image of the $24 \mathrm{~h} \mathrm{SH}$ aged in $0.1 \mathrm{wt} \%$ PAA solution shown as an inset in $(\mathrm{c})$.

previous study. ${ }^{23}$ Background subtraction and data treatment were performed using the Irena package ${ }^{35}$ while data analysis was done using the NIST SANS Analysis package ${ }^{36}$ from which the described model was used without further modification, both within IGOR Pro (Wavemetrics, Inc.).

Enzyme Entrapment and Activity. The enzyme retention within the $\mathrm{SH}$ matrix was studied by using $\mathrm{SH}$ loaded with glucose oxidase (GOx) (EC 1.1.3.4, from Aspergillus niger, 100-250 units/mg, $\left.M_{\mathrm{w}} \sim 160 \mathrm{kDa}\right)$. The $\mathrm{SH}$ were fabricated as previously described, employing $2.0 \mathrm{wt} \%$ CCNF dispersions containing GOx concentrations of 3.1, 6.2, 12.5, 25.0, 50.0, and $75.0 \mu \mathrm{g} / \mathrm{mL}$. A GOx stock solution, prepared in phosphate buffer (100 mM, pH 6), was used to reach the specific concentrations required. The GOx-loaded $\mathrm{SH}$ were thoroughly rinsed in DI water and immersed in a reaction well (Costar 48-well plate) containing $125 \mu \mathrm{L}$ of phosphate buffer (100 $\mathrm{mM}, \mathrm{pH} 6)$. Afterward, the well plate was placed on an orbital shaker, and an aqueous glucose solution (D-(+)-glucose, $99 \%$, Sigma-Aldrich) was added to reach a final concentration of $44 \mathrm{mM}$ in $500 \mu \mathrm{L}$. To quantify the produced $\mathrm{H}_{2} \mathrm{O}_{2}$, aliquots of the continuous media (20 $\mu \mathrm{L}$ ) were withdrawn every $5 \mathrm{~min}$ (for $25 \mathrm{~min}$ ) and mixed with horseradish peroxidase, HRP (EC Type II, EC 1.11.1.7, from horseradish, 150-250 units/mg solid), phosphate buffer, and Amplex Red (ThermoFisher Scientific) to reach final concentrations of 7.5 U/ $\mathrm{mL}, 20 \mathrm{mM}$, and $5 \mu \mathrm{g} / \mathrm{mL}$, respectively. The product of Amplex Red oxidation, resorufin, produced in a 1:1 stoichiometric ratio with $\mathrm{H}_{2} \mathrm{O}_{2}$ was quantified by using fluorescence spectroscopy; the samples measured in a black 96-well plate by using a plate reader (FLUOstar Omega, BMG-LABTECH, excitation and emission of 540 and 590 $\mathrm{nm}$, respectively). The $\mathrm{H}_{2} \mathrm{O}_{2}$ concentration was calculated by using a standard curve employing known concentrations (provided by ThermoFisher Scientific and confirmed by titration against potassium permanganate). The GOx activity was determined by the conversion rate of the substrate (glucose) into the reaction product $\left(\mathrm{H}_{2} \mathrm{O}_{2}\right)$ per unit time and per unit volume $\left(\mathrm{U} \mathrm{mL}^{-1}\right)$.

The reusability experiment was performed by cyclically monitoring the activity of the GOx-loaded SH upon repetitive catalytic cycles (four cycles) over a time span of 8 days. Freshly prepared $\mathrm{SH}$, utilizing the GOx-loaded CCNF dispersion made on day 1, were employed as control samples. All the samples were stored at $4{ }^{\circ} \mathrm{C}$, and the GOx-loaded $\mathrm{SH}$ were thoroughly rinsed before and after each catalytic cycle and separately stored in $1.5 \mathrm{~mL}$ phosphate buffer (100 $\mathrm{mM}, \mathrm{pH} 6$ ). The reported values were obtained from the average of three independent samples.

\section{RESULTS AND DISCUSSION}

Structure and Stability. The stability of the SH was found to be strongly dependent on the aging media. The SH swell in DI water while acquiring long-term stability (several months) in a media containing concentrations of $\mathrm{NaCl}$ greater than 10
$\mathrm{mM}$. Even when tested at $80^{\circ} \mathrm{C}$ in $100 \mathrm{mM} \mathrm{NaCl}$ solution, the $\mathrm{SH}$ did not undergo significant changes. On this ground, the structure-to-stability relationship of the $\mathrm{SH}$ was evaluated as a function of aging media at different osmotic pressures, $\Pi_{\mathrm{m}}$.

At first, the morphological evidence of the core-shell structure of the SH was obtained upon breakage of the SH in DI water (Figure 2a). The SH-shell did not redisperse over the probed time due to the strong CCNF-PAA complexation. Contrarily, the structure within the SH-core slowly dispersed over time, indicating the presence of uncomplexed CCNF. The presence of a core-shell structure suggests that at the moment in which the CCNF dispersion is extruded, dropwise, into a PAA aqueous solution the CCNF-PAA complexation at the interface of the droplet-shaped CCNF dispersion (see Figure 1 ) is fast, and the resulting SH-shell hinders further migration of the PAA into the SH-core. Moreover, because of the liquidlike properties of the extruded CCNF dispersion, the uncomplexed CCNF in the SH-core also preserved the liquid-like feature. Microscope imaging of the SH-shell (Figure $2 \mathrm{~b}$ ) displayed a thickness of ca. $1 \mu \mathrm{m}$, confirming that the $\mathrm{SH}$ could be well depicted by a core-shell structure, containing uncomplexed CCNF in the core and a CCNF-PAA complex across the SH/water interface, composing the SH-shell (depicted in Figure 1). On the basis of the phenomenological characterization of Chollakup et al., we define the CCNFPAA complexation across the $\mathrm{SH} /$ water interface as a complex precipitate. $^{4}$

Solutes can pass through the $\mathrm{SH}$-shell if their size is similar or smaller than the typical mesh size of the SH-shell; this threshold is herein termed the cutoff size of the SH-shell. To qualitatively assess the cutoff size, the SH were loaded with surface-active molecules, and their leakage was investigated by probing $\gamma$ of the media containing unbroken or broken $\mathrm{SH}$ (Figure 2c). Although the amphiphilic molecules were chosen to avoid strong interactions (e.g., electrostatic) with the building blocks of the $\mathrm{SH}$, to highlight the effect of their $M_{\mathrm{w}}$ on their entrapment/release, selective interactions cannot be ruled out. In addition, it must be noticed that this technique does not probe the release kinetics of the loaded amphiphilic species; rather, it solely enables evaluation of their leakage or entrapment. Adsorption of the surface active molecules in these systems to the W/A interface will be influenced by several factors such as their concentration, amphiphilicity, and $M_{\mathrm{w}}$, and so this study does not provide a means to evaluate release kinetics. F-127, having a $M_{\mathrm{w}}$ of $12.6 \mathrm{kDa}$, displayed 


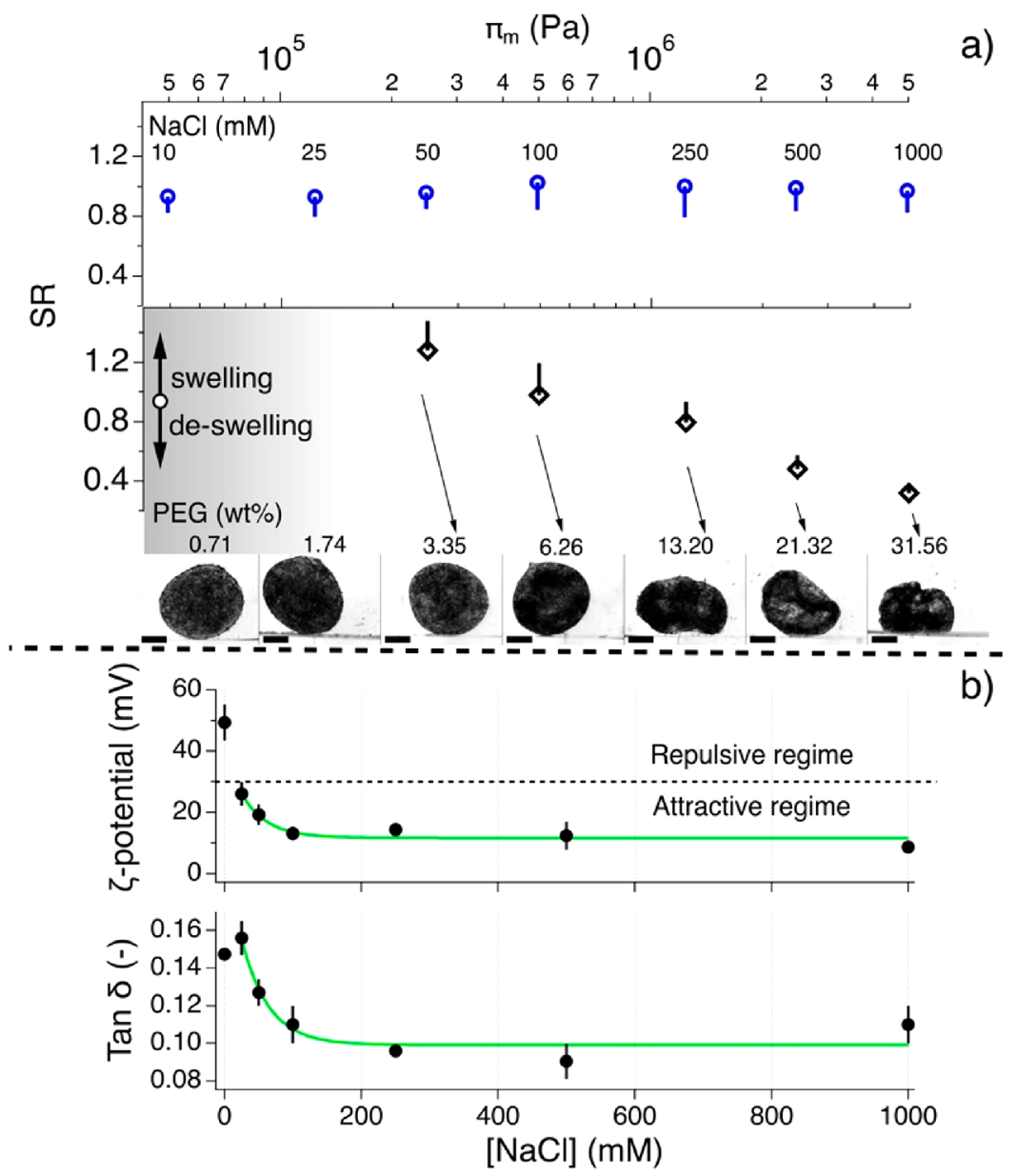

Figure 4. (a) Swelling ratio (SR) as a function of $\Pi_{\mathrm{m}}$ for $\mathrm{NaCl}$ (top) and PEG (bottom) solutions along with images of SH with PEG. Data points are labeled with concentration of $\mathrm{NaCl}(\mathrm{mM})$ and PEG (wt \%). Data points for the SH at PEG concentrations $\leq 1.74$ wt \% (including SH in DI water) were not acquired due to the pronounced swelling and fracture of the SH-shell as displayed by the gray background. (b, top) $\zeta$-potential measurements and (b, bottom) $\tan \delta$ of the $2.0 \mathrm{wt} \% \mathrm{CCNF}$ hydrogels shown as a function of $\mathrm{NaCl}$ concentration. The lines are drawn to guide the eye.

complete release, as shown by almost superimposable $\gamma$ curves before and after breakage, with, in both cases, a strong decrease of the air-water surface tension due to the presence of F-127 at the interface. Contrarily, the probed amphiphilic molecules with $M_{\mathrm{w}} \geq 380 \mathrm{kDa}$ (2HEC-380 and 2HEC-1300) did not leak from the $\mathrm{SH}$ matrix, as indicated by the unchanged $\gamma \approx 72$ $\mathrm{mN} / \mathrm{m}$ before breakage, while a sudden drop is observed after breakage due to adsorption of the released amphiphilic molecules to the W/A interface. This experiment revealed the semipermeable nature of the SH-shell and the ability of the $\mathrm{SH}$ to encapsulate large macromolecules while allowing small molecules to permeate through. Moreover, the unreleased molecules with $M_{\mathrm{w}} \geq 380 \mathrm{kDa}$ from the $\mathrm{SH}$ further suggest that the PAA $\left(M_{\mathrm{v}} \sim 450 \mathrm{kDa}\right)$ used to create the complex precipitate cannot migrate through the $\mathrm{SH}$-shell after it has been formed.

The SH swelling rate in media containing DI water, 1000 $\mathrm{mM} \mathrm{NaCl}$, and 0.1 wt \% PAA was monitored to gain information regarding the $\mathrm{SH}$ stability over time. The $\mathrm{SH}$ aged in DI water showed remarkable swelling over time $(t)$ up to fracture, occurring at ca. $2400 \mathrm{~s}$, clearly noticeable by the spillage of the CCNF dispersion from the $\mathrm{SH}$, as well as scattered $A_{i} / A_{0}$ data points over time (Figure $3 \mathrm{a}$ ). This phenomenon suggests that the $\mathrm{SH}$ swelling occurs by stretching and thinning of the SH-shell up to the formation of localized fracture points, from which the liquid-like CCNF dispersion present in the $\mathrm{SH}$-core spills out. Moreover, the presence of a liquid-like $\mathrm{SH}$-core supports the hypothesis that the CCNF-PAA complexation solely occurs across the SHwater interface, with the resulting $\mathrm{SH}$-shell shielding the PAA penetration into the $\mathrm{SH}$-core.

The $\mathrm{SH}$ aged in $1000 \mathrm{mM} \mathrm{NaCl}$ solution showed minimal swelling up to ca. $1200 \mathrm{~s}$, after which a steady state was reached (Figure $3 \mathrm{~b}$ ). When $\mathrm{SH}$ were aged in the 0.1 wt $\%$ PAA solution, the swelling rate was constant over the experimental time, and no fracture of the SH-shell was observed up to $24 \mathrm{~h}$ (Figure 3c, inset). It is expected that upon swelling the increase in stress along the $\mathrm{SH}$-shell would induce fractures as previously described for DI water. However, the suppressed fracture of the $\mathrm{SH}$-shell upon continuous $\mathrm{SH}$ swelling in $0.1 \mathrm{wt}$ $\%$ PAA indicates that upon generation of new surface area the uncomplexed CCNF of the SH-core is exposed to the $\mathrm{SH} /$ water interface and quickly complexes with PAA in the aging media, the PAA acting as a "patch".

Comparison of the three aging media showed that the swelling rate of the $\mathrm{SH}$, as captured by $k=\frac{\mathrm{d}\left(A_{i} / A_{0}\right)}{\mathrm{d} t}$, was substantially greater for DI water compared to the $0.1 \mathrm{wt} \%$ PAA and $1000 \mathrm{mM} \mathrm{NaCl}$ media, respectively (values of $k\left(\mathrm{~s}^{-1}\right)$ shown in Figure 3). In principle, these dissimilarities could be 

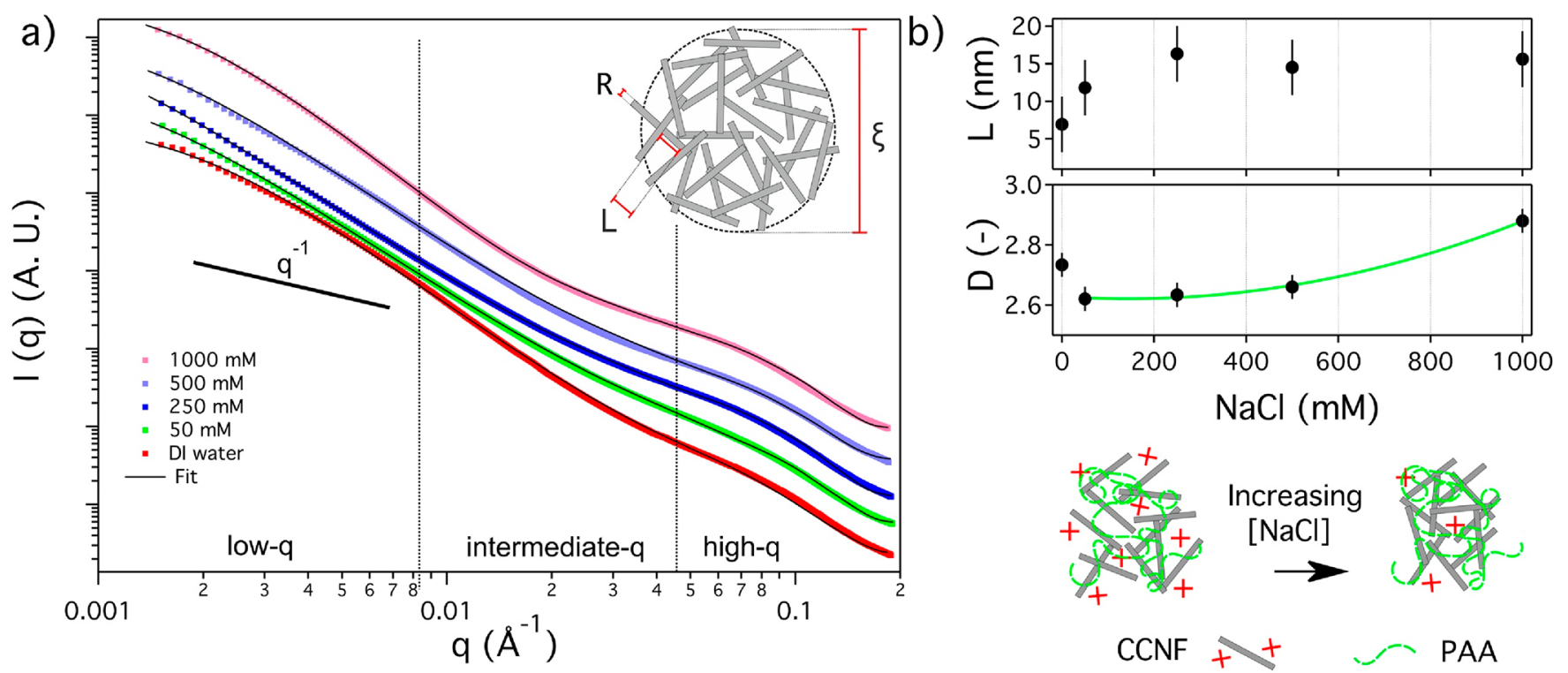

Figure 5. (a) SAXS patterns of the CCNF-PAA films at different $\mathrm{NaCl}$ concentration fitted using a model of fractal cylinders. The scheme depicts the rod-like CCNF and parameters used in the model of fractal cylinders. (b) $L$ (top) and $D$ (center) values obtained by fitting of the fractal model to the SAXS data. The line is drawn to guide the eye. (b, bottom) Schematic representation of the possible mechanism of CCNF aggregation upon $\mathrm{NaCl}$ addition.

justified by the mismatch of the osmotic pressure in the $\mathrm{SH}$ $\left(\Pi_{\mathrm{SH}}\right)$ and $\Pi_{\mathrm{m}}$. However, for the case of $1000 \mathrm{mM} \mathrm{NaCl}$, electrostatic interactions between the charged moieties of the $\mathrm{SH}\left(\mathrm{NR}_{4}{ }^{+}\right.$and $\mathrm{RCOO}^{-}$for CCNF and PAA, respectively) and the electrolyte-rich media need to be accounted for. In this regard, colloidal stability has often been described as the balance between repulsive electrostatic forces and attractive forces, where ionic strength diminishes electrostatic repulsion between particles, leading to dominant attractive forces. Specifically for the case of rod-like particles, it has been shown that their assembly, induced by the increase of ionic strength, leads to the formation of a percolated network with pronounced elastic properties. ${ }^{37,38}$

As such, to evaluate the role of the osmotic pressure of the media on the SH stability, a systematic study of the $\mathrm{SH}$ swelling behavior was conducted in media containing different concentration ranges of $\mathrm{NaCl}$ or $\mathrm{PEG}$ at comparable values of $\Pi_{\mathrm{m}}$. The use of nonionic poly(ethylene glycol) (PEG) allowed the investigation of the $\mathrm{SH}$ swelling behavior due to changes in osmotic pressure, $\Pi_{\mathrm{m}}$. Contrarily, the use of $\mathrm{NaCl}$ coupled changes in $\Pi_{\mathrm{m}}$ and charge screening of both CCNF and PAA. The SH-shell enables the retention of CCNF, present in the $\mathrm{SH}$-core, while allowing migration of both $\mathrm{NaCl}$ and PEG. It is expected that a mismatch in osmotic pressure as $\Pi_{\mathrm{SH}}>\Pi_{\mathrm{m}}$ leads to water migration from the media toward the inside of the $\mathrm{SH}$, resulting in a swelling ratio, $\mathrm{SR}>1$, while a mismatch in osmotic pressure as $\Pi_{\mathrm{SH}}<\Pi_{\mathrm{m}}$ would lead to an opposite trend and a $\mathrm{SR}<1$. However, the $\mathrm{SH}$ did not exhibit substantial swelling or deswelling over a large span of $\mathrm{NaCl}$ concentrations, and consequently $\Pi_{\mathrm{m}}$, tested; the $\mathrm{SR} \cong 1$ (Figure $4 \mathrm{a}$, top). Because different swelling behaviors are expected upon changes in $\Pi_{\mathrm{m}}$, we hypothesize, based on the swelling theory of ionic polymeric networks, that the increase of ionic strength gradually weakens CCNF-PAA binding but enhances the CCNF interactions due to charge screening and hydrophobic or hydrogen bonding interactions between the cellulose particle surfaces, augmenting the elasticity of the network and suppressing both swelling and deswelling. ${ }^{39}$ To test the hypothesis, a concentration series of a nonionic polymer, PEG, solutions were prepared to match the $\Pi_{\mathrm{m}}$ of the $\mathrm{NaCl}$ solutions. As expected, the use of PEG revealed a clear transition from a swelling $\left(\Pi_{\mathrm{m}}\right.$ below $\cong 5 \times 10^{5} \mathrm{~Pa} \cong 66.26$ wt $\%$ PEG ) to a deswelling regime upon increasing $\Pi_{\mathrm{m}}$ above $5 \times$ $10^{5} \mathrm{~Pa}$ (Figure 4a, bottom), a missing feature for the case of the $\mathrm{NaCl}$ containing media. The lack of further swelling at the lower PEG concentrations $(\leq 1.74$ wt $\%)$ and the sedimented CCNF at the bottom of the vial indicated that swelling occurred up to the SH-shell fracture. As such, this experiment revealed that the swelling and deswelling of the $\mathrm{SH}$ could be either modulated via the osmotic pressure of the uncharged medium or even strongly suppressed through modulation of the ionic strength in the media, supporting our hypothesis. The remarkable survival of the $\mathrm{SH}$ in $100 \mathrm{mM} \mathrm{NaCl}$ solution at 80 ${ }^{\circ} \mathrm{C}$ also demonstrates the strong interactions present in the shell of these capsules in the presence of electrolyte.

The strength of the SH arises from both the shell and the core; hence, the two contributions must be considered separately. Because the SH-core is PAA-free, the effect of $\mathrm{NaCl}$ on the $\mathrm{SH}$-core was probed through $\zeta$-potential and oscillatory rheology measurements of the $2.0 \mathrm{wt} \% \mathrm{CCNF}$ hydrogels (not in the $\mathrm{SH}$ form) to gain information about interfibrillar interactions within the $\mathrm{SH}$-core (Figure $4 \mathrm{~b}$ ). The $\zeta$-potential of CCNF was found to decrease upon $\mathrm{NaCl}$ addition, indicating neutralization of the positively charged moieties via electrostatic screening as previously reported for similar systems. ${ }^{37,38}$ It is noted that the value of $\mid \zeta$-potentiall $=$ $30 \mathrm{mV}$ sets an empirical threshold between repulsive (electrostatic dominated) and attractive (van der Waals and hydrogen bonds dominated) regimes and finds its root in the Derjaguin-Landau-Verwey-Overbeek (DLVO) theory. ${ }^{40}$ Noticeably, addition of $10 \mathrm{mM} \mathrm{NaCl}$ was sufficient to overcome the repulsive electrostatic regime, leading to enhancement of attractive interfibrillar attractions. ${ }^{40}$

The $\tan \delta$ of the CCNF hydrogels followed a similar trend as for $\zeta$-potential, indicating the formation of a more pronounced gel-like interconnected network upon addition of $\mathrm{NaCl}$, as 
previously observed for similar systems. ${ }^{37}$ These results support the hypothesis of network strengthening in the $\mathrm{SH}$ core due to charge screening and augmented CCNF-CCNF interactions. However, the properties of the solid precipitated $\mathrm{SH}$-shell upon $\mathrm{NaCl}$ addition were not directly assessed.

Because insights into the $\mathrm{SH}$-shell structure at the nanometer length scale are very complicated to obtain in situ, we mimicked the SH-shell structure by preparing CCNFPAA films aged at different $\mathrm{NaCl}$ concentrations and probing their microstructure via SAXS (Figure 5a). All the SAXS patterns displayed similar high- $q$ patterns, associated with the CCNF cross section, as for the pure CCNF (Figure S2), confirming the main contribution of CCNF to the scattering intensity in the CCNF-PAA films as well as unvaried CCNF cross section upon addition of $\mathrm{NaCl}$.

A pronounced difference between samples was noticeable in the intermediate- $q$ and low- $q$ range. In these ranges, greater length scales than the CCNF cross section are probed (e.g., persistence length). The SAXS patterns did show the absence of a Guinier region (a plateau in the low- $q$ region), indicating that the characteristic dimension of the object is not fully probed. Moreover, the low- $q$ slopes substantially diverged from a $q^{-1}$, slope which is associated with scattering from dilute solutions of elongated objects, indicating a pronounced level of interactions between CCNF. ${ }^{37}$

To better compare the SAXS patterns, the CCNF-PAA were modeled as fractal aggregates composed of cylinders, resembling CCNF, as building blocks. ${ }^{32}$ (as schematically represented in Figure 5a, inset). In this model, the contribution of the PAA is not included due to its negligible contribution to the scattering intensity. This is justified by the greater CCNF wt $\%$ in the CCNF-PAA film (composed by ca. 10.5 times the amount of CCNF compared to PAA, on a dry basis, as estimated for a $1: 1$ stoichiometric ratio $(f=0.5)$ between the oppositely charged moieties (see the Supporting Information for an estimation of $f$ )). The $L$ yielded by the model, corresponding to the characteristic node-to-node distance between CCNF (Figure 5a, inset), did not show a pronounced variation in the $50-1000 \mathrm{mM} \mathrm{NaCl}$ range, indicating that the characteristic node-to-node distance of the fractal network is constant. However, a smaller value of $L$ was obtained in the absence of $\mathrm{NaCl}$ (Figure 5b, top), suggesting that the presence of electrolyte weakens PAA-CCNF interactions, allowing some initial network expansion in the presence of $\mathrm{NaCl}$. It is noted that the value of the correlation length of the aggregate, $\xi$, was found to be much greater (at least by 1 order of magnitude) than the values of radius of gyration, $R_{\mathrm{g}}$, of the cylindrically shaped CCNF $\left(R_{\mathrm{g}}{ }^{2}=\left(\right.\right.$ radius $\left.^{2} / 2\right)+\left(\right.$ length ${ }^{2} /$ 12)), ${ }^{41}$ indicating that both $L$ and $D$ are independent of the value of $\xi$ (values of $\xi$ in Figure S3). ${ }^{36}$

The mass fractal dimension, $D$, scales with the number of primary CCNF particles, $i$, as $i \propto\left(\frac{\xi}{R_{\mathrm{g}}}\right)^{D}$, assessing the density of CCNF within $\xi .^{42}$ The values of $D$ obtained from the fractal model followed a gradual increase with increasing $\mathrm{NaCl}$ concentration from 50 to $1000 \mathrm{mM}$, indicating aggregation and densification of CCNF (Figure 5b, center, and schematic in Figure $5 b$, bottom). In the literature, the response of oppositely charged polyelectrolytes to subsequent addition of salt has been reported to (i) reduce aggregation up to dissolution, (ii) induce additional aggregation, or (iii) have a negligible effect depending on the characteristic of the polyelectrolytes. $^{4,5,7,43-45}$ Specific instances of (i) were provided by Hamad et al. ${ }^{5}$ and Spruijt et al., ${ }^{7}$ who found an increase in mesh size and a more pronounced liquid-like behavior in polyelectrolyte mixtures upon an increase of ionic strength due to diminishing polycation-polyanion attractive forces. The case of additional aggregation (ii) upon addition of $\mathrm{NaCl}$ has been reported by Dautzenberg and co-workers, ${ }^{43-45}$ termed secondary aggregation, and mainly attributed to the presence of strong ionic groups and a mismatch in charge density between the oppositely charged polyelectrolytes. Similarly, it is possible that, for the CCNF-PAA complexation the enhanced aggregation of the fibrillar particles upon $\mathrm{NaCl}$ addition arises due to the charge screening of neighboring, uncomplexed, charged moieties of CCNF, allowing these to aggregate further (schematic in Figure $5 b$, bottom). It is noted that the pattern of increasing $\mathrm{D}$ upon $\mathrm{NaCl}$ addition does not apply to the case of $0 \mathrm{mM} \mathrm{NaCl}$, where $D$ displayed a greater value than in the $50-500 \mathrm{mM} \mathrm{NaCl}$ range. This may be addressed by the substantially smaller building blocks of the network, as captured by the characteristic node-to-node distance between fibrils, $L$, in the absence of $\mathrm{NaCl}$, which would allow better packing and consequently a denser network.

SH as Microreactors for Biocatalysis. Hydrogel beads have been broadly exploited for the encapsulation and release of active components. ${ }^{46}$ Nonetheless, the long-term entrapment of macromolecules has been stressed as an outstanding challenge, limiting their application and reusability. ${ }^{47,48}$ On this ground, we investigated the entrapment of a model enzyme, GOx, within $\mathrm{SH}$ by monitoring its catalytic activity. As expected, the GOx activity increased as a function of the concentration loaded into the SH. More interestingly, the activity of the GOx-loaded $\mathrm{SH}$ approached a plateau at higher concentrations, suggesting limited substrate diffusion into the $\mathrm{SH}$ matrix (Figure 6). The $50 \mu \mathrm{g} / \mathrm{mL}$ GOx-loaded SH were

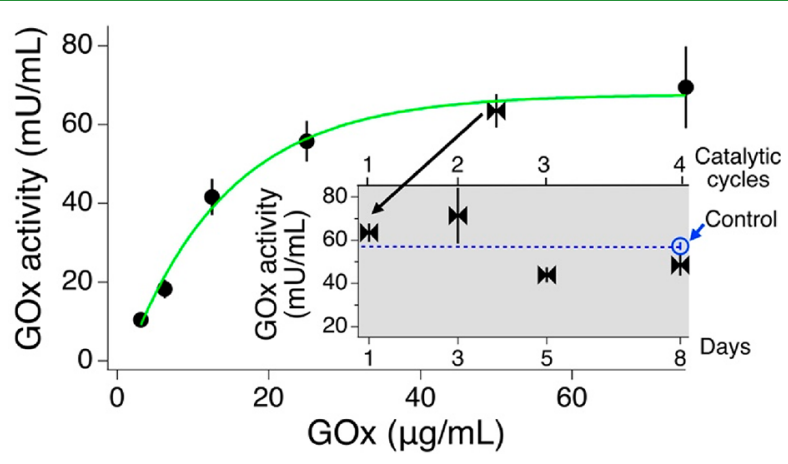

Figure 6. Catalytic activity of GOx-loaded $\mathrm{SH}$ as a function of the initial GOx concentration in the CCNF dispersion (employed for the production of the $\mathrm{SH}$ ); the line is drawn to guide the eye. Inset displays the activity of GOx-loaded $\mathrm{SH}$ upon catalytic cycles and as a function of storage time $\left(4^{\circ} \mathrm{C}\right)$ expressed in days.

employed to test their reusability over a time span of 8 days (Figure 6, inset). The GOx activity showed excellent retention of activity upon storage and catalytic cycles with only a minimal decay on the fifth day. The GOx activity measured on the eighth day was compared to a control sample of freshly prepared GOx-loaded $\mathrm{SH}$, fabricated utilizing an 8 day vintage GOx-loaded CCNF dispersion. The GOx activity in the control sample showed a similar value to the GOx-loaded $\mathrm{SH}$ on the eighth day, indicating that no significant GOx leakage 
occurred upon storage or catalytic cycles. Moreover, the control sample showed a slightly lower value compared to the GOx-loaded SH on day 1, suggesting that the long-term GOx storage in aqueous media may be an influencing factor on its activity. The ability of the $\mathrm{SH}$ to retain enzymes for several days is a feature which differs from the previously reported alginate beads where substantial protein leakage occurred within a few hours. ${ }^{47,48}$ Moreover, the SH resilience in saline solutions, as demonstrated here by storage in phosphate buffer and $\mathrm{NaCl}$ differs from for instance, alginate beads which undergo dissolution under similar conditions. ${ }^{14,15,46}$ This highlights the potential of these $\mathrm{SH}$ in biotechnological applications.

\section{CONCLUSION}

This work aimed to characterize $\mathrm{SH}$ produced by a chargedriven interfacial complexation process. We found that via extruding, dropwise, a dispersion of positively charged cellulose nanofibrils, CCNF, into an aqueous bath containing negatively charged polymer, PAA, $\mathrm{SH}$ were formed. The $\mathrm{SH}$ were characterized by a liquid-like core, composed of uncomplexed CCNF and a solid-like shell formed by the CCNF-PAA complexation. The $\mathrm{SH}$-shell did not redisperse in pure water and saline environments due to the strong CCNF-PAA complexation and possessed characteristic features of a semipermeable membrane, allowing the release of small macromolecules $(\leq 12.6 \mathrm{kDa})$ while retaining larger ones. Moreover, the semipermeable nature of the $\mathrm{SH}$-shell allowed a tunable swelling behavior of the $\mathrm{SH}$ according to the osmotic pressure of the continuous media. We found that insensitivity to swelling was achieved in saline media, associated with the enhancement of interfibrillar interactions in both the SH-core and the SH-shell. Furthermore, we validated the applicability of $\mathrm{SH}$ as suitable matrixes for physical enzyme entrapment, allowing the use and reuse of $\mathrm{SH}$ as microreactors from which substrate and product are freely able to migrate through the $\mathrm{SH}$ while avoiding enzyme leakage.

\section{ASSOCIATED CONTENT}

\section{SI Supporting Information}

The Supporting Information is available free of charge at https://pubs.acs.org/doi/10.1021/acsapm.9b01086.

Conductometric titration of CCNF, estimation of the molar ratio $(f)$, SAXS data of the $2.0 \mathrm{wt} \%$ CCNF dispersion and values of $\xi$, yielded by the model of fractal cylinders, as a function of $\mathrm{NaCl}$ concentration (PDF)

\section{AUTHOR INFORMATION}

\section{Corresponding Authors}

Vincenzo Calabrese - Department of Chemistry, University of Bath, Bath BA2 7AY, United Kingdom; (1) orcid.org/0000-

0001-5974-9217; Email: vc355@bath.ac.uk, 355calabrese@ gmail.com

Karen J. Edler - Department of Chemistry, University of Bath, Bath BA2 7AY, United Kingdom; 이이.org/0000-00015822-0127; Email: k.edler@bath.ac.uk

\section{Authors}

Davide Califano - Department of Chemistry and Centre for Sustainable Chemical Technologies, University of Bath, Bath BA2 7AY, United Kingdom
Marcelo A. da Silva - Department of Chemistry, University of Bath, Bath BA2 7AY, United Kingdom; (1) orcid.org/00000002-1413-4021

Julien Schmitt - Department of Chemistry, University of Bath, Bath BA2 7AY, United Kingdom; O orcid.org/0000-00023452-6655

Saffron J. Bryant - Department of Chemistry, University of Bath, Bath BA2 7AY, United Kingdom; (1) orcid.org/00000002-7202-3004

Kazi M. Zakir Hossain - Department of Chemistry, University of Bath, Bath BA2 7AY, United Kingdom

Ana M. Percebom - Department of Chemistry, Pontifical Catholic University of Rio de Janeiro (PUC-Rio), 22451-900 Rio de Janeiro, RJ, Brazil; 이이이.org/0000-0002-1511-8656

Aurora Pérez Gramatges - Department of Chemistry, Pontifical Catholic University of Rio de Janeiro (PUC-Rio), 22451-900 Rio de Janeiro, RJ, Brazil; 이 orcid.org/00000001-5951-6130

Janet L. Scott - Department of Chemistry and Centre for Sustainable Chemical Technologies, University of Bath, Bath BA2 7AY, United Kingdom; O orcid.org/0000-0001-80212860

Complete contact information is available at:

https://pubs.acs.org/10.1021/acsapm.9b01086

\section{Notes}

The authors declare no competing financial interest.

\section{ACKNOWLEDGMENTS}

The authors thank the EPRSC for funding parts of this project (grant EP/N033310/1). V.C. and D.C. thank the University of Bath for funding their $\mathrm{PhD}$ studentships. We thank the Diamond Light Source for access to beamline I22 (SM204091) that contributed to the results presented here, and we thank Dr N. Terrill, Dr. T. Snow, and Dr A. Smith for their assistance with the experiment on beamline I22. Data supporting this work are freely accessible in the Bath research data archive system at DOI: 10.15125/BATH-00760.

\section{REFERENCES}

(1) Overbeek, J. T. G.; Voorn, M. J. Phase Separation in Polyelectrolyte Solutions. Theory of Complex Coacervation. J. Cell. Comp. Physiol. 1957, 49, 7-26.

(2) Spruijt, E.; Westphal, A. H.; Borst, J. W.; Cohen Stuart, M. A.; van der Gucht, J. Binodal Compositions of Polyelectrolyte Complexes. Macromolecules 2010, 43, 6476-6484.

(3) Kizilay, E.; Kayitmazer, A. B.; Dubin, P. L. Complexation and Coacervation of Polyelectrolytes with Oppositely Charged Colloids. Adv. Colloid Interface Sci. 2011, 167 (1-2), 24-37.

(4) Chollakup, R.; Smitthipong, W.; Eisenbach, C. D.; Tirrell, M. Phase Behavior and Coacervation of Aqueous Poly(Acrylic Acid)Poly(Allylamine) Solutions. Macromolecules 2010, 43 (5), 25182528.

(5) Hamad, F. G.; Chen, Q.; Colby, R. H. Linear Viscoelasticity and Swelling of Polyelectrolyte Complex Coacervates. Macromolecules 2018, 51, 5547-5555.

(6) Spruijt, E.; Cohen Stuart, M. A.; Van Der Gucht, J. Linear Viscoelasticity of Polyelectrolyte Complex Coacervates. Macromolecules 2013, 46 (4), 1633-1641.

(7) Spruijt, E.; Leermakers, F. A. M.; Fokkink, R.; Schweins, R.; Van Well, A. A.; Cohen Stuart, M. A.; Van Der Gucht, J. Structure and Dynamics of Polyelectrolyte Complex Coacervates Studied by Scattering of Neutrons, X-Rays, and Light. Macromolecules 2013, 46 (11), 4596-4605. 
(8) De Geest, B. G.; Sanders, N. N.; Sukhorukov, G. B.; Demeester, J.; De Smedt, S. C. Release Mechanisms for Polyelectrolyte Capsules. Chem. Soc. Rev. 2007, 36 (4), 636-649.

(9) De Geest, B. G.; Sukhorukov, G. B.; Möhwald, H. The Pros and Cons of Polyelectrolyte Capsules in Drug Delivery. Expert Opin. Drug Delivery 2009, 6 (6), 613-624.

(10) Kaufman, G.; Boltyanskiy, R.; Nejati, S.; Thiam, A. R.; Loewenberg, M.; Dufresne, E. R.; Osuji, C. O. Single-Step Microfluidic Fabrication of Soft Monodisperse Polyelectrolyte Microcapsules by Interfacial Complexation. Lab Chip 2014, 14 (18), 3494-3497.

(11) Monteillet, H.; Hagemans, F.; Sprakel, J. Charge-Driven CoAssembly of Polyelectrolytes across Oil-Water Interfaces. Soft Matter 2013, 9 (47), 11270.

(12) Calabrese, V.; da Silva, M. A.; Schmitt, J.; Hossain, K. M. Z.; Scott, J. L.; Edler, K. J. Charge-Driven Interfacial Gelation of Cellulose Nanofibrils across the Water/Oil Interface. Soft Matter 2020, 16 (2), 357-365.

(13) Segale, L.; Giovannelli, L.; Mannina, P.; Pattarino, F. Calcium Alginate and Calcium Alginate-Chitosan Beads Containing Celecoxib Solubilized in a Self-Emulsifying Phase. Scientifica 2016, 2016, 1-8.

(14) Rolland, L.; Santanach-Carreras, E.; Delmas, T.; Bibette, J.; Bremond, N. Physicochemical Properties of Aqueous Core Hydrogel Capsules. Soft Matter 2014, 10 (48), 9668-9674.

(15) Bremond, N.; Santanach-Carreras, E.; Chu, L. Y.; Bibette, J. Formation of Liquid-Core Capsules Having a Thin Hydrogel Membrane: Liquid Pearls. Soft Matter 2010, 6 (11), 2484-2488.

(16) Johnston, A. P. R.; Cortez, C.; Angelatos, A. S.; Caruso, F. Layer-by-Layer Engineered Capsules and Their Applications. Curr. Opin. Colloid Interface Sci. 2006, 11 (4), 203-209.

(17) Lacík, I.; Briššová, M.; Anilkumar, A. V.; Powers, A. C.; Wang, T. New Capsule with Tailored Properties for the Encapsulation of Living Cells. J. Biomed. Mater. Res. 1998, 39 (1), 52-60.

(18) Briššová, M.; Lacík, I.; Powers, A. C.; Anilkumar, A. V.; Wang, T. Control and Measurement of Permeability for Design of Microcapsule Cell Delivery System. J. Biomed. Mater. Res. 1998, 39 (1), 61-70.

(19) Krajčovič, T.; Bučko, M.; Vikartovská, A.; Lacík, I.; Uhelská, L.; Chorvát, D.; Neděla, V.; Tihlaříková, E.; Gericke, M.; Heinze, T.; Gemeiner, P. Polyelectrolyte Complex Beads by Novel Two-Step Process for Improved Performance of Viable Whole-Cell BaeyerVilliger Monoxygenase by Immobilization. Catalysts 2017, 7 (11), 353.

(20) Laurenti, E.; dos Santos Vianna, A., Jr. Enzymatic Microreactors in Biocatalysis: History, Features, and Future Perspectives. Biocatalysis 2016, 1 (1), 148-165.

(21) Rodrigues, R. C.; Ortiz, C.; Berenguer-Murcia, Á.; Torres, R.; Fernández-Lafuente, R. Modifying Enzyme Activity and Selectivity by Immobilization. Chem. Soc. Rev. 2013, 42 (15), 6290-6307.

(22) Secundo, F. Conformational Changes of Enzymes upon Immobilisation. Chem. Soc. Rev. 2013, 42 (15), 6250-6261.

(23) Calabrese, V.; Muñoz-García, J. C.; Schmitt, J.; da Silva, M. A.; Scott, J. L.; Angulo, J.; Khimyak, Y. Z.; Edler, K. J. Understanding Heat Driven Gelation of Anionic Cellulose Nanofibrils: Combining Saturation Transfer Difference (STD) NMR, Small Angle X-Ray Scattering (SAXS) and Rheology. J. Colloid Interface Sci. 2019, 535, 205-213.

(24) Zaman, M.; Xiao, H.; Chibante, F.; Ni, Y. Synthesis and Characterization of Cationically Modified Nanocrystalline Cellulose. Carbohydr. Polym. 2012, 89 (1), 163-170.

(25) Hasani, M.; Cranston, E. D.; Westman, G.; Gray, D. G. Cationic Surface Functionalization of Cellulose Nanocrystals. Soft Matter 2008, 4 (11), 2238-2244.

(26) Swift, T.; Swanson, L.; Geoghegan, M.; Rimmer, S. The PHResponsive Behaviour of Poly(Acrylic Acid) in Aqueous Solution Is Dependent on Molar Mass. Soft Matter 2016, 12 (9), 2542-2549.

(27) Courtenay, J. C.; Ramalhete, S. M.; Skuze, W. J.; Soni, R.; Khimyak, Y. Z.; Edler, K. J.; Scott, J. L. Insights into Cationic
Cellulose Nanofibril Hydrogel Structure through NMR Spectroscopy and Small Angle Neutron Scattering. Soft Matter 2018, 14, 255-263.

(28) Bourne, R.; Bourne, R. ImageJ. Fundam. Digit. Imaging Med. 2010, 9 (7), 185-188.

(29) Stanley, C. B.; Strey, H. H. Measuring Osmotic Pressure of Poly(Ethylene Glycol) Solutions by Sedimentation Equilibrium Ultracentrifugation. Macromolecules 2003, 36 (18), 6888-6893.

(30) Morrison, F. Electrophoresis of a Particle of Arbitrary Shape. J. Colloid Interface Sci. 1970, 34 (2), 210-214.

(31) Bakker, H. E.; Besseling, T. H.; Wijnhoven, J. E. G. J.; Helfferich, P. H.; Van Blaaderen, A.; Imhof, A. Microelectrophoresis of Silica Rods Using Confocal Microscopy. Langmuir 2017, 33 (4), $881-890$.

(32) Teixeira, J. Small-Angle Scattering by Fractal Systems. J. Appl. Crystallogr. 1988, 21 (6), 781-785.

(33) Golosova, A. A.; Adelsberger, J.; Sepe, A.; Niedermeier, M. A.; Lindner, P.; Funari, S. S.; Jordan, R.; Papadakis, C. M. Dispersions of Polymer-Modified Carbon Nanotubes: A Small-Angle Scattering Investigation. J. Phys. Chem. C 2012, 116 (29), 15765-15774.

(34) Chen, C.-Y.; Chan, S.-H.; Li, J.-Y.; Wu, K.-H.; Chen, H.-L.; Chen, J.-H.; Huang, W.-Y.; Chen, S.-A. Formation and ThermallyInduced Disruption of Nanowhiskers in Poly(3-Hexylthiophene)/ Xylene Gel Studied by Small-Angle X-Ray Scattering. Macromolecules 2010, 43, 7305-7311.

(35) Ilavsky, J.; Jemian, P. R. Irena: Tool Suite for Modeling and Analysis of Small-Angle Scattering. J. Appl. Crystallogr. 2009, 42 (2), 347-353.

(36) Kline, S. R. Reduction and Analysis of SANS and USANS Data Using IGOR Pro. J. Appl. Crystallogr. 2006, 39 (6), 895-900.

(37) Schmitt, J.; Calabrese, V.; Da Silva, M. A.; Lindhoud, S.; Alfredsson, V.; Scott, J. L.; Edler, K. J. TEMPO-Oxidised Cellulose Nanofibrils; Probing the Mechanisms of Gelation: Via Small Angle XRay Scattering. Phys. Chem. Chem. Phys. 2018, 20 (23), 1601216020.

(38) Fukuzumi, H.; Tanaka, R.; Saito, T.; Isogai, A. Dispersion Stability and Aggregation Behavior of TEMPO-Oxidized Cellulose Nanofibrils in Water as a Function of Salt Addition. Cellulose 2014, 21 (3), 1553-1559.

(39) Flory, P. J. Principles of Polymer Chemistry; Cornell University Press: Ithaca, NY, 1953; pp 576-594.

(40) Schramm, L. L. Suspensions: Basic Principles. Adv. Chem. Ser. 1996, 251, 21-22.

(41) Hammouda, B. Parts A-G. In Probing Nanoscale Structures The SANS Toolbox; National Institute of Standards and Technology Center for Neutron Research: Gaithersburg, MD, 2010; pp 1-326.

(42) Lazzari, S.; Nicoud, L.; Jaquet, B.; Lattuada, M.; Morbidelli, M. Fractal-like Structures in Colloid Science. Adv. Colloid Interface Sci. 2016, 235, 1-13.

(43) Dautzenberg, H.; Karibyants, N. Polyelectrolyte Complex Formation in Highly Aggregating Systems. 1. Effect of Salt: Polyelectrolyte Complex Formation in the Presence of $\mathrm{NaCl}$. Macromol. Chem. Phys. 1999, 200 (1), 118-125.

(44) Dautzenberg, H.; Jaeger, W. Effect of Charge Density on the Formation and Salt Stability of Polyelectrolyte Complexes. Macromol. Chem. Phys. 2002, 203 (14), 2095-2102.

(45) Dautzenberg, H.; Kriz, J. Response of Polyelectrolyte Complexes to Subsequent Addition of Salts with Different Cations. Langmuir 2003, 19 (13), 5204-5211.

(46) Gombotz, W. R.; Wee, S. F. Protein Release from Alginate Matrices. Adv. Drug Delivery Rev. 2012, 64, 194-205.

(47) Zhang, Z.; Zhang, R.; Chen, L.; McClements, D. J. Encapsulation of Lactase ( $\beta$-Galactosidase) into $\kappa$-CarrageenanBased Hydrogel Beads: Impact of Environmental Conditions on Enzyme Activity. Food Chem. 2016, 200, 69-75.

(48) Zhang, Z.; Zhang, R.; Zou, L.; McClements, D. J. Protein Encapsulation in Alginate Hydrogel Beads: Effect of PH on Microgel Stability, Protein Retention and Protein Release. Food Hydrocolloids 2016, 58, 308-315. 